\title{
Continuous cell washing and mixing driven by an ultrasound standing wave within a microfluidic channel $\dagger+$
}

\author{
Jeremy J. Hawkes, ${ }^{* a}$ Robert W. Barber, ${ }^{b}$ David R. Emerson ${ }^{b}$ and W. Terence Coakley ${ }^{c}$ \\ a School of Chemical Engineering and Analytical Science, The University of Manchester, \\ PO Box 88, Sackville Street, Manchester, UK M60 1QD. \\ E-mail: J.Hawkes@manchester.ac.uk; Tel: +441613068884 \\ ${ }^{b}$ Centre for Microfluidics and Microsystems Modelling, CCLRC Daresbury Laboratory, \\ Daresbury, Warrington, Cheshire, UKWA4 4AD. E-mail: R.W.Barber@dl.ac.uk; \\ D.R.Emerson@dl.ac.uk; Tel: +441925603221 \\ c School of Biosciences, Cardiff University, Cardiff, UK CF10 $3 T L$. \\ E-mail: Coakley@Cardiff.ac.uk; Tel: +44 2920874287
}

Received 2nd June 2004, Accepted 6th September 2004

First published as an Advance Article on the web 27th September 2004

\begin{abstract}
Ultrasound standing wave radiation force and laminar flow have been used to transfer yeast cells from one liquid medium to another (washing) by a continuous field-flow fractionation (FFF) approach. Two co-flowing streams, a cell-free suspending phase (flow rate $>50 \%$ of the total flow-through volume) and a yeast suspension, were introduced parallel to the nodal plane of a $3 \mathrm{MHz}$ standing wave resonator. The resonator was fabricated to have a single pressure nodal plane at the centre line of the chamber. Laminar flow ensured a stable interface was maintained as the two suspending phases flowed through the sound field. Initiation of the ultrasound transferred cells to the cell-free phase within $0.5 \mathrm{~s}$. This particle transfer procedure circumvents the pellet formation and re-suspension steps of centrifuge based washing procedures. In addition, fluid mixing was demonstrated in the same chamber at higher sound pressures. The channel operates under negligible backpressure (cross-section, $0.25 \times 10 \mathrm{~mm}$ ) and with only one flow convergence and one flow division step, the channel cannot be easily blocked. The force acting on the cells is small; less than that experienced in a centrifuge generating $100 \mathrm{~g}$. The acoustically-driven cell transfer and mixing procedures described may be particularly appropriate for the increasingly complex operations required in molecular biology and microbiology and especially for their conversion to continuous flow processes.
\end{abstract}

\section{Introduction}

\subsection{Cell washing and mixing applications}

Cell washing and mixing procedures are required in many molecular biology and microbiology protocols. Taking a plasmid DNA extraction as a typical example, the procedure includes seven medium changes with most steps requiring centrifugation for up to $10 \mathrm{~min}$ and pellet re-suspension or surface binding/ washing treatments using multiple media with mixing or exchange. ${ }^{1}$ While significant attention has been directed towards the problem of mixing in microfluidic channels, ${ }^{2}$ progress towards micro-scale procedures and non-robotic-automation for analytical and processing technology is slowed by the different handling needs of fluids at the macro- and micro-scales. We report here on a technology that takes full advantage of the laminar flow properties of micro-scale fluidics and combines this with ultrasound to create a system for either washing cells or mixing fluids, of potential application to many fields.

\subsection{Ultrasound cell manipulation}

In an ultrasound standing wave, cells or particles in suspension experience a number of forces. In the present paper, we focus

$\dagger$ Electronic supplementary information (ESI) available: movie of cell washing showing experimental visualisation of cell transfer, pdf showing CFD predictions of sodium fluorescein diffusion across the channel at a high and low flow rate. See http://www.rsc.org/suppdata/ $\mathrm{lc} / \mathrm{b} 4 / \mathrm{b} 408045 \mathrm{a} /$

\$ The contents of this paper include material subject to Crown Copyright 2004 Dstl. on the principle acoustic force, $F_{u s}$ (eqn. (1)), which generally drives cells towards the pressure nodal plane. As described by Gould and Coakley, ${ }^{3}$ the principle acoustic force is given by:

$$
F_{u s}=-\left(\frac{P_{0}^{2} V_{\mathrm{p}} \beta_{\mathrm{f}} \pi}{2 \lambda}\right)\left(\frac{\left(5 \rho_{\mathrm{p}}-2 \rho_{\mathrm{f}}\right)}{\left(2 \rho_{\mathrm{p}}+\rho_{\mathrm{f}}\right)}-\frac{\beta_{\mathrm{p}}}{\beta_{\mathrm{f}}}\right) \sin \left(\frac{4 \pi z}{\lambda}\right)
$$

where $P_{0}$ is the peak sound pressure, $\rho_{\mathrm{p}}$ and $\rho_{\mathrm{f}}$ are the particle and suspending fluid densities, respectively, $\beta_{\mathrm{p}}$ and $\beta_{\mathrm{f}}$ are the compressibilities of the particle and fluid, $\lambda$ is the wavelength of sound in the suspending phase, $V_{\mathrm{p}}$ is the particle volume and $z$ is the distance normal to the pressure node.

Single half-wavelength continuous flow filtration and separation systems have been developed by Mandralis and Feke $^{4}$ and Yasuda. ${ }^{5}$ Unlike larger multi-wavelength filters, ${ }^{6,7}$ which operate by forming clumps, half-wavelength filters produce a single focused band of particles (without the use of hydrodynamic focusing techniques ${ }^{8}$ ) in highly controllable laminar flow conditions that even allow filtration of a single particle. This methodology has been further advanced by Hawkes et al. ${ }^{9,10}$ to produce a smaller system operating at higher frequencies to avoid the potentially destructive effects of cavitation. The approach is now incorporated into a siliconbased system. ${ }^{11}$ An alternative use of the high frequency methodology has been utilised by Gherardini et al. ${ }^{12}$ to position cells within a gel.

In the present paper, experimental and CFD results introduce two further developments of the half-wavelength approach; in the first, cells are transferred from one liquid medium to another without the need for a concentration (pellet 
formation) step, as required during centrifugal washing procedures. In the second, cells are efficiently mixed within the suspending fluid.

Ultrasonic mixing is an established macro-scale technique that uses cavitation effects produced by low frequency ultrasound $(<1 \mathrm{MHz})$ to mix the fluids. Similar techniques can also be applied to micro-systems. For example, Yang et al. ${ }^{13}$ employed a frequency of $60 \mathrm{kHz}$ to provide fluid mixing in a micro-chamber. However, cavitation produces cell disruption and therefore low frequencies are generally inappropriate for delicate manipulation of cell suspensions. Yasuda ${ }^{14}$ has reported the use of $3.5 \mathrm{MHz}$ sound to mix a suspension of red blood cells with a cell-free liquid and observed negligible cell disruption. He also observed mixing of two fluids while holding cells at the nodes of a standing wave. We have seen similar fluid mixing in our chamber at high voltages and extended measurements to lower voltages where we identified a power dependent switch between mixing and separating conditions.

\subsection{Cell washing: principle of operation}

The method adopted in the present system can be described as a continuous field-flow fractionation (FFF) approach ${ }^{15,16}$ where the force field is the ultrasound standing wave radiation force on a cell. The process is shown schematically in Fig. 1b. Two fluids, $\mathrm{A}$ and $\mathrm{B}$, are brought into contact with each other without mixing in a rectangular cross section duct. Fluid $\mathrm{A}$ is a cell-free receiving fluid ( $>50 \%$ of the total flow rate), and fluid $\mathrm{B}$, a suspension of cells ( $<50 \%$ of the total flow rate). The two fluids pass through an ultrasound standing wave field that moves the cells to the centre of the duct, thereby transferring them from fluid B to fluid A. After transfer, the cells and their initial host fluid are removed through separate outlets. Successful proof-of-principle experiments describing particle fractionation $^{4,17,18}$ included intrusive flow splitters along the

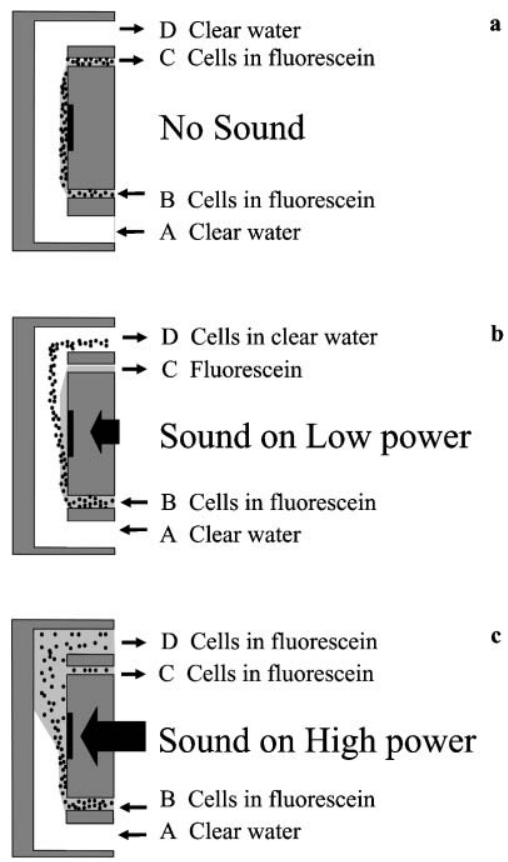

Fig. 1 Schematic representation of ultrasonic chamber showing three idealised conditions. (a) Sound off. Fluids enter inlets A and B, and leave through outlets $\mathrm{C}$ and $\mathrm{D}$, with minimal crossover of cells or fluorescein. (b) Sound on at low power. The sound field drives cells entering at B towards the nodal plane at the centre of the channel while the fluorescein molecules remain relatively unaffected. (c) Sound on at high power. Cells and fluorescein molecules are driven across the channel by acoustic streaming forces to produce identical outputs from outlets $\mathrm{C}$ and $\mathrm{D}$. flow direction. By necessity, the use of inline flow splitters requires significantly larger chambers ( $>1 \mathrm{~mm}$ high). In the present study, the flow was divided through ducts meeting at right angles, allowing the construction of a smaller chamber $(0.25 \mathrm{~mm}$ sound path). This permits the use of higher frequencies, thereby reducing the probability of cavitation and producing greater forces on the cells, enabling either the manipulation of smaller cells or the use of higher flow rates.

\section{Method}

\subsection{Chamber construction details}

Fig. 2 shows a schematic view of the internal ducts of the ultrasonic chamber. The device is a modification of a previously constructed flow system ${ }^{9}$ and has a main (vertical) duct of $0.25 \times 10 \mathrm{~mm}$ cross-section and a total length of $51 \mathrm{~mm}$. The narrow $(0.25 \mathrm{~mm})$ walls are formed from a polydimethylsiloxane (PDMS) (Sylgard 184, Dow Corning) gasket around the $10 \mathrm{~mm}$ wide channel. This narrow dimension is established by a $0.25 \mathrm{~mm}$ thick brass shim around the gasket when the parts are clamped together. One of the wide $(10 \mathrm{~mm})$ walls of the duct was formed from a $1.5 \mathrm{~mm}$ thick quartz glass (Spectrocil B, Chandos Intercontinental, Chapel en le Frith, Derbyshire, UK). Within the sound field, the quartz functions as an ultrasound reflector ( $3 / 4$ wavelengths at $3 \mathrm{MHz})$. The second $10 \mathrm{~mm}$ wide wall was formed from $3.1 \mathrm{~mm}$ thick stainless steel (Stavax, Uddeholm, Mölndal, Sweden) allowing the sound to be coupled from the piezo-ceramic to the liquid filled duct ( $3 / 2$ wavelengths at $3 \mathrm{MHz}$ ). The stainless steel layer contained four slots forming the inlet and outlet ports, A-D, cut at right angles to the duct (Fig. 2b). Slots A and D are $2 \times$ $10 \mathrm{~mm}$ cross-section while slots $\mathrm{B}$ and $\mathrm{C}$ are $0.25 \times 10 \mathrm{~mm}$ cross-section. A $0.4 \mathrm{~mm}$ deep recess in the steel confines the PDMS gasket around the channel.

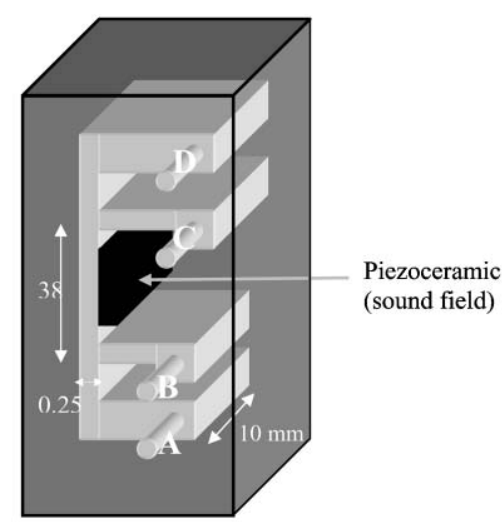

a

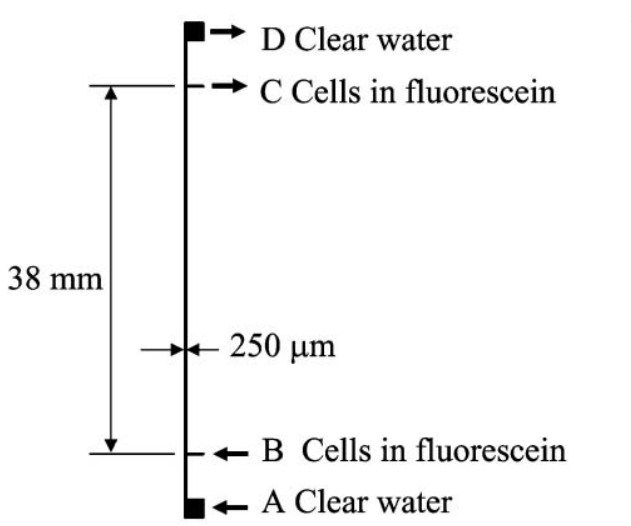

b

Fig. 2 (a) 3D diagrammatic representation of ultrasonic cell washing chamber (not to scale). (b) Scale drawing of the channels in the ultrasonic chamber. 
Sound was produced by a PZ26 piezo-ceramic plate (Ferroperm, Krisgard, Denmark) with dimensions $30 \times$ $30 \times 0.67 \mathrm{~mm}$ (i.e. $3 \mathrm{MHz}$ fundamental resonance thickness). Electrodes on the piezo-ceramic were etched ${ }^{9}$ to reduce the active area to $10 \times 20 \mathrm{~mm}$. The transducer was then attached by epoxy resin to the outer face of the stainless steel layer halfway between slots B and C (see Fig. 1 and 2).

\subsection{Electrical drive}

A sinusoidal voltage of $18 \mathrm{~V}_{\mathrm{p}-\mathrm{p}}$ (unless otherwise stated) was applied from an amplifier (Model 240L, ENI, Rochester, NY) to the piezo-ceramic at a frequency of $2.96 \mathrm{MHz}$ produced by a signal generator (Hewlett Packard 3326A). The phase angle between current and voltage, measured with an Agilent (54621A) oscilloscope, was a minimum at this frequency.

\subsection{Sample preparations}

De-gassed water was produced by boiling for $2 \mathrm{~min}$, sealing in an airtight screw cap bottle and leaving to cool to room temperature before use. Although not essential, degassed water was used to reduce the possibility of bubble formation caused by temperature gradients at the walls of the tubing. Dried yeast (Boots, Nottingham, UK) was reconstituted in degassed water containing $1 \mathrm{mM}$ sodium fluorescein (MW 376; approximately $0.45 \mathrm{~nm}$ radius) (Sigma). The absence of nutrients prevented yeast cell budding and division, thus maintaining an average cell radius close to $2.5 \mu \mathrm{m}$. $^{7}$ Microscope observations suggest there is little variation in the radius of the cells, with most being between 2 and $3 \mu \mathrm{m}$. The suspension was constantly stirred to maintain homogeneity and break up any clumps.

\subsection{Flow system}

The system is usually orientated so that the flow direction is vertically upwards. In this orientation, gravity cannot transport cells from the nodal line and any bubbles that enter will easily pass through the system without becoming trapped. The device has two inlets ( $\mathrm{A}$ and $\mathrm{B}$ ) which meet the main duct at right angles allowing the fluids to converge and pass $38 \mathrm{~mm}$ along the main duct where they are exposed to the sound field $(20 \mathrm{~mm}$ long). The fluid is then divided and leaves through two outlet ducts (C and D). In order to obtain an output from $\mathrm{D}$ that was apparently clear of sodium fluorescein by visual inspection, the flow rate through $\mathrm{D}$ was reduced to $\sim 90 \%$ of the inflow at $\mathrm{A}$.

Fluid was transported through the chamber with near pulsefree-flow using a combination of peristaltic pumps (Gilson Mini-puls 3) and air-damped pulse smoothing consisting of pipettes and narrow tubing as described previously by Hawkes and Coakley. ${ }^{9}$ The following flow rates were used unless stated otherwise, but in all cases the ratio of flow rates between channels remained constant. Pumps were placed on outlet $\mathrm{C}$ (flow rate, $\left.\mathrm{FR}_{\mathrm{C}}=2.6 \mathrm{ml} \mathrm{min}{ }^{-1}\right)$, outlet $\mathrm{D}\left(\mathrm{FR}_{\mathrm{D}}=\right.$

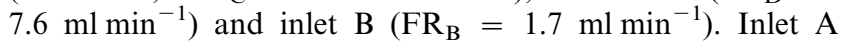
was connected without a pump to a reservoir of cell-free water (fluid A) $\left(\mathrm{FR}_{\mathrm{A}}=8.5 \mathrm{ml} \mathrm{min}^{-1}\right)$. The total volumetric flow rate through the sound field was $10.2 \mathrm{ml} \mathrm{min}^{-1}$. This corresponds to a Reynolds number of approximately 37 (see Section 3.2) and therefore laminar flow will occur throughout the entire system. The interface between the $17 \%$ of the total flow volume entering inlet $\mathrm{B}$ and the $83 \%$ entering inlet $\mathrm{A}$ is found (when the parabolic flow profile is taken into account) to be approximately $65 \mu \mathrm{m}$ from the wall. The interface between the flow leaving through outlet C ( $25.5 \%$ of the total flow) and outlet D ( $74.5 \%$ of the total flow) is $83 \mu \mathrm{m}$ from the wall. At a flow rate of $10.2 \mathrm{ml} \mathrm{min}^{-1}$, fluid at this distance from the wall will pass through the sound field in $0.22 \mathrm{~s}$. The yeast cells, however, take slightly longer as they travel from the slower flow at the side of the channel towards the centreline.

\subsection{Measurement of yeast and fluorescein concentrations}

The separation efficiency of the device was determined by measuring the concentrations of yeast cells and sodium fluorescein in $20 \mathrm{ml}$ samples collected from the peristaltic pumps drawing from outlet ducts, $\mathrm{C}$ and $\mathrm{D}$ (Fig. 2). To reduce the influence of the outlet dead volume ( $\sim 2 \mathrm{ml})$, sampling was only carried out after $20 \mathrm{ml}$ had passed through outlet C. Control samples were collected with the sound off for each flow rate and cell concentration used.

Yeast concentrations in both samples were determined from cell counts on a Neubauer improved haemacytometer (Assistent, Germany). The samples were then centrifuged (500 g, $10 \mathrm{~min}$ ) and the sodium fluorescein levels were obtained from supernatant absorbance measurements at $485 \mathrm{~nm}$ (Shimadzu UV-2401PC spectrophotometer).

\subsection{Transfer and separation calculations}

The number of yeast cells passing through each port per second was obtained from the product of the flow rate and concentration (for example, $\mathrm{FR}_{\mathrm{C}} \cdot[\mathrm{C}]_{\text {yeast }}$ ). The percentage of yeast transferred, $T(\%)$, from inlet $\mathrm{B}$ to outlet $\mathrm{D}$ was estimated from the measured number of cells leaving outlets $C$ and $D$ :

$$
T(\%)=100 \frac{\mathrm{FR}_{\mathrm{D}}[\mathrm{D}]_{\text {yeast }}}{\mathrm{FR}_{\mathrm{D}}[\mathrm{D}]_{\text {yeast }}+\mathrm{FR}_{\mathrm{C}}[\mathrm{C}]_{\text {yeast }}}
$$

A similar approach was used to calculate the transfer of sodium fluorescein.

The transfer percentages can then be used to define the separation (or relative transfer) between the yeast and sodium fluorescein:

$$
\text { Separation }=\frac{T(\%)_{\text {yeast }}}{T(\%)_{\text {fluorescein }}}
$$

\section{Computer simulations}

\subsection{Basic methodology}

Computational fluid dynamics (CFD) simulations were used to provide a better understanding of the flow characteristics of the ultrasonic washing chamber and to provide quantitative estimates of the expected level of diffusion between inlet $\mathrm{B}$ and outlet D. The numerical simulations employed the commercial computational fluid dynamics solver, CFD$\mathrm{ACE}+\left(\mathrm{CFD}\right.$ Research Corporation, Huntsville, USA $\left.{ }^{19}\right)$. The computer model uses a finite-volume algorithm to solve the non-linear Navier-Stokes equations governing the conservation of mass and momentum within the fluid. In addition, the software solves the advection-diffusion equation to predict the flow and mixing of a user defined scalar species.

\subsection{Reynolds number}

The total volumetric flow rate through the system was $10.2 \mathrm{ml} \mathrm{min}^{-1}$, corresponding to a mean velocity of $0.068 \mathrm{~m} \mathrm{~s}^{-1}$ in the $0.25 \times 10 \mathrm{~mm}$ cross-section. When considering noncircular ducts, the Reynolds number is traditionally defined using the hydraulic diameter, $D_{\mathrm{h}}$, as the characteristic length scale: ${ }^{20}$

$$
D_{\mathrm{h}}=\frac{4 \times \text { area }}{\text { wetted perimeter }}=\frac{4 W d}{2(W+d)}=\frac{2 W d}{(W+d)}
$$

where $W$ is the width and $d$ is the depth of the channel. The Reynolds number can then be defined as follows:

$$
R e=\frac{\rho_{\mathrm{f}} v_{\mathrm{av}} D_{\mathrm{h}}}{\eta}
$$

where $\rho_{\mathrm{f}}$ is the fluid density $\left(\mathrm{kg} \mathrm{m}^{-3}\right), v_{\mathrm{av}}$ is the average velocity 
through the duct $\left(\mathrm{m} \mathrm{s}^{-1}\right)$ and $\eta$ is the dynamic viscosity of the fluid $\left(\mathrm{kg} \mathrm{m}^{-1} \mathrm{~s}^{-1}\right)$. For a total flow rate of $10.2 \mathrm{ml} \mathrm{min}^{-1}$, the Reynolds number is approximately 37 , well below the transition to turbulence, implying the flow within the system is laminar.

\subsection{Computational details}

Since the cell washing system employs a high aspect ratio flow channel $(0.25 \times 10 \mathrm{~mm}$ cross-section $)$, the fully-developed velocity profile will be parabolic across the smaller $(0.25 \mathrm{~mm})$ dimension but almost uniform across the wider $(10 \mathrm{~mm})$ dimension. A two-dimensional grid composed of approximately 105000 grid points was employed in the numerical simulations giving run times to convergence of approximately $2 \mathrm{~h}$ on a Compaq Alpha Server ES40 computer $(667 \mathrm{MHz}$ EV67 64-bit processor).

The diffusion coefficients for sodium fluorescein (approximately $0.45 \mathrm{~nm}$ radius $^{21}$ ) and yeast (approximately $2.5 \mu \mathrm{m}$ radius $^{7}$ ) were specified to be $5.3 \times 10^{-10} \mathrm{~m}^{2} \mathrm{~s}^{-1}$ and $9.7 \times$ $10^{-14} \mathrm{~m}^{2} \mathrm{~s}^{-1}$, respectively. These values were estimated using the Stokes-Einstein equation:

$$
D=\frac{k T}{6 \pi R \eta}
$$

where $k$ is Boltzmann's constant $\left(1.380662 \times 10^{-23} \mathrm{~J} \mathrm{~K}^{-1}\right), T$ is the temperature $(\mathrm{K}), \eta$ is the fluid viscosity $\left(\mathrm{kg} \mathrm{m}^{-1} \mathrm{~s}^{-1}\right)$ and $R$ is the radius of the particle $(\mathrm{m})$.

Temperature effects were incorporated into the numerical model by defining the density, viscosity and diffusion coefficients as functions of temperature, $T$.

\section{Results}

\subsection{Fluid separation in the absence of sound}

In the idealised situation depicted in Fig. 1(a), the two coflowing streams are shown alongside each other with no transfer of sodium fluorescein or yeast cells to the clear water before the fluids are separated through the two outlets. Experimentally, it was found that visually clear water was obtained from outlet D by setting its flow to $\sim 90 \%$ of the clear water flow rate into $\mathrm{A}$. This ratio of flow rates between inlet $\mathrm{A}$ and outlet $\mathrm{D}$ has been used throughout the paper with the exception of the CFD calculations for Fig. 3. Spectrophotometer measurements of the sodium fluorescein concentration revealed that $9.1 \%$ of the fluorescein was still being transferred. The measured transfer rate is in good agreement with the CFD prediction $(8.7 \%)$ shown in Fig. 3, demonstrating that diffusion is the dominant mechanism for transferring fluorescein to

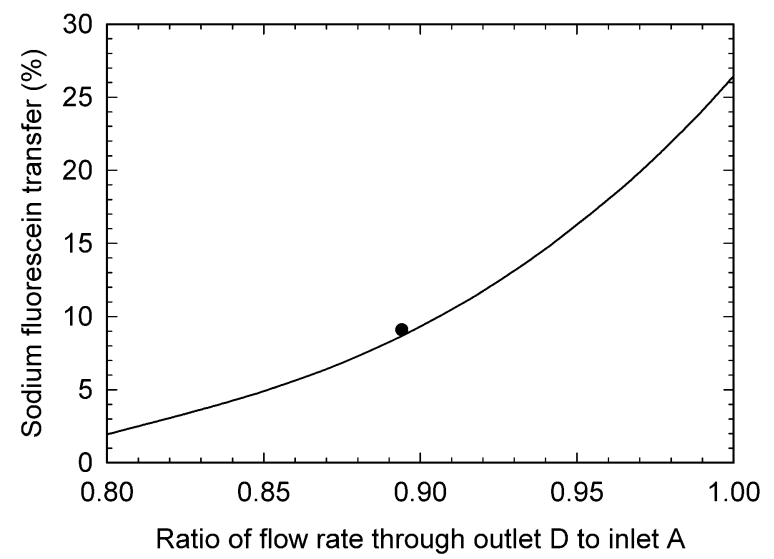

Fig. 3 Transfer of sodium fluorescein to outlet D as a function of the flow rate ratio between outlet $D$ and inlet $A$ in the absence of sound. Total flow rate remained constant at $10.2 \mathrm{ml} \mathrm{min}^{-1}$. CFD predictions $(-)$ and experimental result outlet D. CFD simulations were also used to calculate the transfer of sodium fluorescein for other flow rate ratios through ports $\mathrm{A}$ and $\mathrm{D}$. The CFD results indicate that setting the outlet flow through $\mathrm{D}$ to be $\sim 80 \%$ of the clear water inflow would reduce the transfer of fluorescein to less than $2 \%$. This four-fold benefit was predicted by CFD after the experiments were carried out and therefore not implemented in the present experimental study.

Fig. 4 shows the transfer of sodium fluorescein to outlet D as a function of total flow rate in the absence of sound. The experimentally measured transfer of fluorescein decreases with flow rate to approximately $5 \%$ at a flow rate of $16.3 \mathrm{ml} \mathrm{min}^{-1}$. Again very good correlation is observed between the experimental measurements and the CFD simulations. Fig. 4 also shows the transfer of yeast as a function of flow rate and indicates that the transfer of yeast is lower than the transfer of fluorescein at all flow rates. The experimental data range from 1 to $4 \%$ depending upon the flow rate while the CFD simulations predict cell transfer ranging from 1.4 to $1.7 \%$.

\subsection{Separation in the presence of ultrasound}

When the ultrasound was switched on, cells were transported across the interface between the two co-flowing streams to the sound pressure node at the centre of the chamber causing a dramatic increase in the number of cells leaving through outlet D.

4.2.1 Effect of flow rate. The effect of flow rate is illustrated in Fig. 5, which shows that both yeast and sodium fluorescein transfer decrease as the flow rate increases. Comparing Fig. 5 (with sound) to Fig. 4 (without sound), it can be seen that the transfer of yeast increases between 18 and 42 fold. In contrast, the transfer of sodium fluorescein increases by less than $1.2 \%$ at the voltage and yeast concentration utilised in Fig. 5. The ultrasound radiation force has selectively moved yeast cells rather than sodium fluorescein towards the central node position in the chamber. The powerful influence of ultrasound on yeast cells and the minimal effect on fluorescein is predicted by eqn. (1) since the velocity component towards the node due to the acoustic force scales with the square of the particle radius. Yeast cells $(\sim 2.5 \mu \mathrm{m}$ radius $)$ are therefore transported to the node $\sim 3 \times 10^{7}$ times faster than the sodium fluorescein molecules ( $\sim 0.45 \mathrm{~nm}$ radius), provided other acoustic properties are equal. This difference in velocities can be used to separate yeast from sodium fluorescein, although diffusion reduces the effectiveness of the ultrasound separation. Fig. 5

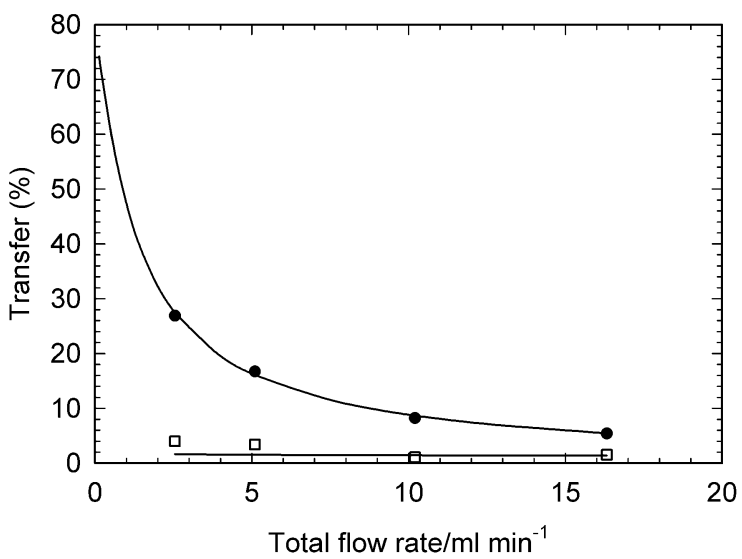

Fig. 4 Transfer of sodium fluorescein and yeast cells to outlet D as a function of total flow rate in the absence of sound. Experimental data: Sodium fluorescein $(\bullet)$ and yeast cells $(\square)$. CFD predictions: (-). Initial yeast cell concentration $1.53 \times 10^{7} \mathrm{ml}^{-1}$. 


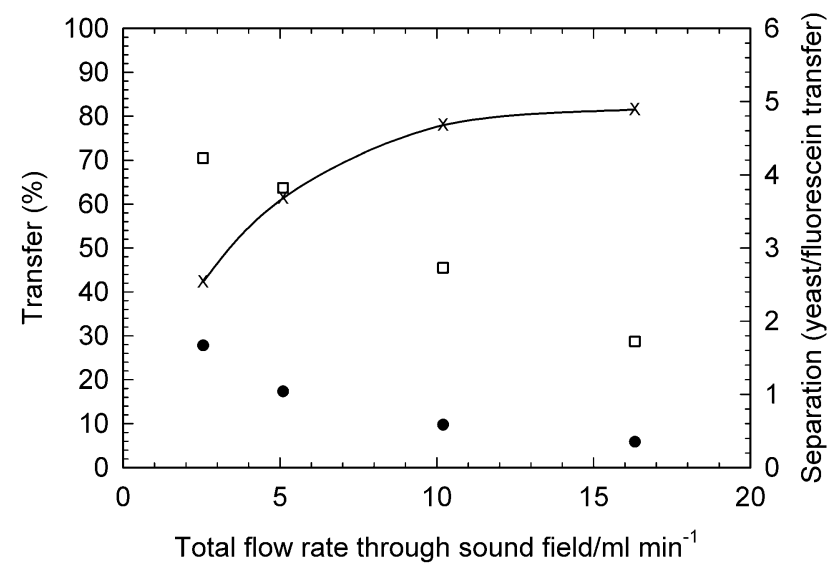

Fig. 5 Transfer of sodium fluorescein and yeast cells to outlet D as a function of total flow rate in the presence of sound. At all flow rates, the transfer of yeast $(\square)$ is greater than the transfer of sodium fluorescein

(O) producing a yeast:fluorescein separation $(x-\times$, right hand $Y$-axis). Initial yeast cell concentration $1.53 \times 10^{7} \mathrm{ml}^{-1}$. Applied voltage $18 \mathrm{~V}_{\mathrm{p}-\mathrm{p}}$.

illustrates the variation in separation efficiency versus flow rate and shows that maximum separation ( 5 fold) occurs above $10 \mathrm{ml} \mathrm{min}{ }^{-1}$.

4.2.2 Effect of drive voltage. Yeast transfer increased with applied voltage (in the absence of any temperature-induced change in resonance frequency, voltage is directly proportional to sound pressure) up to $\sim 24 \mathrm{~V}_{\mathrm{p}-\mathrm{p}}$ but showed a reduction at $29 \mathrm{~V}_{\mathrm{p}-\mathrm{p}}$ (Fig. 6). In contrast, the fluorescein transfer increased at voltages above $18 \mathrm{~V}_{\mathrm{p}-\mathrm{p}}$. In addition, at voltages of $18 \mathrm{~V}_{\mathrm{p}-\mathrm{p}}$ (and above), some of the yeast cells clumped together as described by Spengler et $a l^{22}$ and the clumps were held by the sound field as new suspension flowed past. This clumping of yeast cells disrupts the flow pattern and must be responsible for some of the reduction in the efficiency of yeast transfer at high voltages. Within $3 \mathrm{~min}$ the clumping and build-up reaches a maximum and stabilizes; this was confirmed using an extended test period of $3 \mathrm{~h}$ at the highest voltage. The combination of the yeast and sodium fluorescein transfer efficiencies produces a sharp optimum voltage for separation of $18 \mathrm{~V}_{\mathrm{p}-\mathrm{p}}$ (Fig. 6).

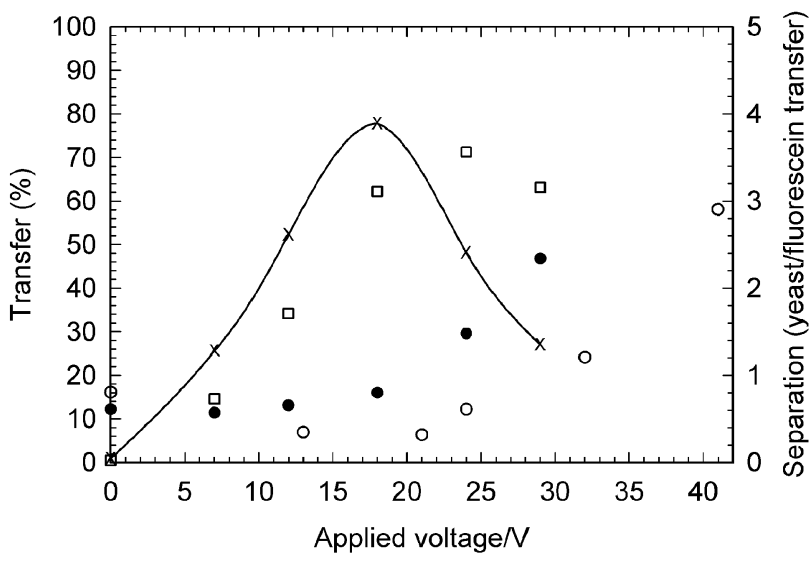

Fig. 6 Transfer of sodium fluorescein and yeast cells to outlet D as a function of applied voltage. Transfer of yeast cells $(\square)$ (initial yeast cell concentration $\left.6.4 \times 10^{7} \mathrm{ml}^{-1}\right)$, transfer of sodium fluorescein in presence of yeast cells $(-)$ (initial yeast cell concentration $6.4 \times 10^{7} \mathrm{ml}^{-1}$ ) and transfer of sodium fluorescein in the absence of yeast cells $(\bigcirc)$. Increasing the voltage accelerates the transfer of yeast $(\square)$ at low voltages and also sodium fluorescein $(\bigcirc)$ above $18 \mathrm{~V}_{\mathrm{p}-\mathrm{p}}$ leading to an optimum voltage for separation $(\times-\times$, right hand $Y$-axis $)$ at around $18 \mathrm{~V}_{\mathrm{p}-\mathrm{p}}$. There is also an indication that mixing is occurring at the highest voltages where yeast transfer falls and there is a near equal transfer of yeast and sodium fluorescein. Flow rate through sound field $10.2 \mathrm{ml} \mathrm{min}^{-1}$.
In the absence of cells, acoustically-driven fluid movement (that may be associated with the complex streaming vortices studied in a rectangular half wavelength chamber similar to that employed here ${ }^{23}$ or to destabilisation of the interface between the flowing liquid phases) is the main mechanism responsible for the increase in sodium fluorescein transfer at the higher voltages. This was concluded from measurements of transfer by sound for cell free sodium fluorescein (Fig. 6). At a voltage of $41 \mathrm{~V}_{\mathrm{p}-\mathrm{p}}, 58 \%$ of the sodium fluorescein was transferred; this large transfer coincided with the chamber becoming noticeably warmer to the touch. The influence of sodium fluorescein transfer by thermal convection was investigated by transfer measurements at $41 \mathrm{~V}_{\mathrm{p}-\mathrm{p}}$ with various chamber orientations (vertical and horizontal, reflector up and reflector down). This produced only minimal variations in the sodium fluorescein transfer (ranging from 54.6 to $58.1 \%$ ). Convection was also considered by CFD modelling of heating effects along a single sidewall using temperature dependent density, viscosity and diffusion coefficients. A $20 \mathrm{~K}$ change in side-wall temperature resulted in less than a $1 \%$ change in sodium fluorescein transfer. CFD simulations also indicate that changing the ambient temperature from $298 \mathrm{~K}$ to $318 \mathrm{~K}$ would only increase the sodium fluorescein transfer from $9 \%$ to $13 \%$, clearly demonstrating that heating effects on their own could not produce the observed 58\% transfer at higher voltages.

The absence of thermal convection can also be determined from the Rayleigh number. ${ }^{24}$ For a horizontal chamber and an assumed temperature difference of $20 \mathrm{~K}$ between the stainless steel and quartz glass walls, the Rayleigh number can be shown to be approximately 6 . This is much less than the critical value of 1700 which marks the onset of thermal convection. Both the experimental and modelling results therefore demonstrate that convection is not a significant transfer mechanism in a chamber of this scale.

The presence of cells increases the sodium fluorescein transfer (Fig. 6), reaching $47 \%$ at only $29 \mathrm{~V}_{\mathrm{p}-\mathrm{p}}$. Some increase in transfer is expected from the deviation of flow due to clumps held in the sound field. Another transfer mechanism will be entrainment of fluid associated with the moving cells. Preliminary flow simulations, however, suggest that entrainment only accounts for an increase of less than $3 \%$. In addition, acoustic scattering by the cells may increase acoustic streaming to further boost the transfer.

4.2.3 Effect of yeast cell concentration. The influence of input yeast cell concentration is shown in Fig. 7 for an applied voltage of $18 \mathrm{~V}_{\mathrm{p}-\mathrm{p}}$ and a total flow rate of $10.2 \mathrm{ml} \mathrm{min}^{-1}$. There is some variation in the yeast cell transfer levels around an average of approximately $54 \%$. The sodium fluorescein

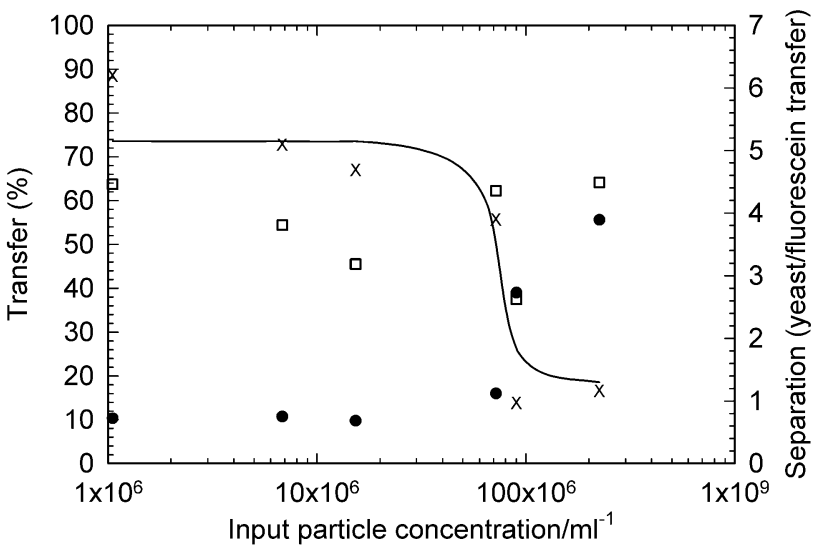

Fig. 7 Transfer of yeast cells $(\square)$ and sodium fluorescein $(\bullet)$ and their separation $(\times$, right hand $Y$-axis, - given as a guide) as a function of yeast concentration. Applied voltage $18 \mathrm{~V}_{\mathrm{p}-\mathrm{p}}$. Flow rate through sound field $10.2 \mathrm{ml} \mathrm{min}^{-1}$. 
transfer, however, shows a clear pattern, increasing at the highest cell concentrations. This produces a decrease in the separation with yeast cell concentration. During the experiment it was noted that the size of clumps held in the sound field increased at higher concentrations and this may have an important influence on the transfer of both the yeast cells and sodium fluorescein.

\section{Discussion}

In the absence of sound, the device is similar to other diffusion based separation systems. ${ }^{25}$ The good agreement between experimental measurements and CFD simulations for the transfer of sodium fluorescein indicates that: (1) diffusion is the dominant mechanism for sodium fluorescein transfer and (2) machining quality is not a significant limitation in the current system (even though the stainless steel walls had many scratches several microns deep). Replacement of the present system with a Micro-Electro-Mechanical-Systems (MEMS) device ${ }^{11}$ is expected to increase consistency and reduce adhesion of bubbles and cells to the rough surfaces of the channel.

Analysis of the results presented here allows us to propose a number of approaches that together could enhance the separation (washing) action of the system by a factor of more than 8: (1) a four-fold reduction in sodium fluorescein transfer can be predicted from Fig. 3, by reducing the ratio of flow through outlet $\mathrm{D}$ to flow through inlet A from 0.89 to 0.80 ; (2) a further two-fold separation improvement could be gained by reducing the distance between inlet $\mathrm{B}$ and outlet $\mathrm{C}$ from $38 \mathrm{~mm}$ to the length of the ultrasound transducer ( $20 \mathrm{~mm}$ ); (3) an application involving the separation of cells from molecules with lower diffusivity would be more efficient than the experimental sodium fluorescein/yeast fractionation examined here. For example, for a flow rate of $10.2 \mathrm{ml} \mathrm{min}{ }^{-1}$, CFD simulations indicate that the transfer of serum albumin $(D=$ $6.5 \times 10^{-11} \mathrm{~m}^{2} \mathrm{~s}^{-1}$ ) by diffusion would be $1.6 \%$ compared to $8.7 \%$ for sodium fluorescein $\left(D=5.3 \times 10^{-10} \mathrm{~m}^{2} \mathrm{~s}^{-1}\right)$. The serum albumin molecules are too small to be moved to the nodal position in the ultrasound standing wave and therefore higher separation levels could be achieved between serum albumin and yeast. Similarly, separation of yeast cells $(\sim 2.5 \mu \mathrm{m}$ radius) from bacteria ( $\sim 0.5 \mu \mathrm{m}$ radius) may also be possible due to the 25 fold difference in velocity between the two cell types in an ultrasound field. With sufficient refinement, the approach could also be used to separate the same type of cells according to the small natural spread in their radii.

\section{Conclusions}

A procedure has been described that can be used to either separate samples as they pass through a low power ultrasound field or mix them in a higher power field. When operating at a flow rate of $10.2 \mathrm{ml} \mathrm{min}^{-1}$, typical transit times through the sound field are less than $0.5 \mathrm{~s}$. For separation and washing operations, this processing time is significantly shorter than that required by a centrifuge. Moreover, unlike traditional centrifuge separations, the present system can operate in a continuous flow mode.

Mixing has been observed at high voltages, and is effective in both the presence and absence of cells. In the present system, the use of high voltages sometimes results in increased temperatures. Experimental observations and CFD results, however, indicate that the dimensions of the chamber are too small to support disruptive thermal convection. We conclude that acoustically-produced non-thermally induced flow drives the mixing observed at high voltages.

The acoustically-driven separation and mixing techniques described here are generic processes that could be widely applied to low Reynolds number fluidic systems. Potential applications include particle and fluid manipulation in both biological and non-biological systems. Mixing is a particular challenge in miniaturised devices and the acoustic action described here should prove to be useful for active control of fluid mixing.

\section{Appendix}

Notation

\begin{tabular}{|c|c|c|c|}
\hline $\begin{array}{l}\text { Latin } \\
d\end{array}$ & $\begin{array}{l}\text { Depth of channel } \\
(\lambda / 2)\end{array}$ & $\left(2.5 \times 10^{-4} \mathrm{~m}\right)$ & $/ \mathrm{m}$ \\
\hline$D$ & Diffusion coefficient & $\begin{array}{l}\left(5.3 \times 10^{-10} \mathrm{~m}^{2} \mathrm{~s}^{-1} \text { for }\right. \\
\text { sodium fluorescein }) \\
\left(9.7 \times 10^{-14} \mathrm{~m}^{2} \mathrm{~s}^{-1}\right. \\
\text { for yeast cells })\end{array}$ & $/ \mathrm{m}^{2} \mathrm{~s}^{-1}$ \\
\hline$D_{\mathrm{h}}$ & $\begin{array}{l}\text { Hydraulic diameter } \\
\text { of channel }\end{array}$ & $\begin{array}{l}(4 \times \text { cross sectional } \\
\text { area/wetted perimeter }) \\
\left(4.878 \times 10^{-4} \mathrm{~m}\right)\end{array}$ & $/ \mathrm{m}$ \\
\hline$F_{\text {us }}$ & $\begin{array}{l}\text { Principle standing } \\
\text { wave ultrasonic } \\
\text { radiation force } \\
\text { on particles }\end{array}$ & & $/ \mathrm{N}$ \\
\hline $\mathrm{FR}_{\mathrm{n}}$ & $\begin{array}{l}\text { Flow rate } \\
\text { through port } n\end{array}$ & & $/ \mathrm{ml} \min ^{-1}$ \\
\hline$k$ & $\begin{array}{l}\text { Boltzmann's } \\
\text { constant }\end{array}$ & $\begin{array}{l}(1.380662 \times \\
\left.10^{-23} \mathrm{~J} \mathrm{~K}^{-1}\right)\end{array}$ & $/ \mathrm{J} \mathrm{K}^{-1}$ \\
\hline$P_{0}$ & $\begin{array}{l}\text { Peak acoustic } \\
\text { pressure amplitude }\end{array}$ & & $/ \mathrm{Pa}$ \\
\hline$R$ & Radius of particle & $\begin{array}{l}\left(2.5 \times 10^{-6} \mathrm{~m}\right. \\
\quad \text { for yeast cells }) \\
\left(0.45 \times 10^{-9}\right. \\
\text { m for sodium } \\
\text { fluorescein molecules })\end{array}$ & $/ \mathrm{m}$ \\
\hline$R e$ & $\begin{array}{l}\text { Reynolds number, } \\
\rho_{\mathrm{f}} v_{\mathrm{av}} D_{\mathrm{h}} / \eta\end{array}$ & & (dimensionless) \\
\hline$T$ & Temperature & & $/ \mathrm{K}$ \\
\hline$T(\%)$ & $\begin{array}{l}\text { Transfer percentage } \\
\text { between inlet B } \\
\text { and outlet D }\end{array}$ & (yeast or fluorescein) & $\%$ \\
\hline$v_{\mathrm{av}}$ & Average flow velocity & & $/ \mathrm{m} \mathrm{s}^{-1}$ \\
\hline$V_{\mathrm{p}}$ & Particle volume & & $/ \mathrm{m}^{3}$ \\
\hline W & Channel width & $(0.01 \mathrm{~m})$ & $/ \mathrm{m}$ \\
\hline$z$ & $\begin{array}{l}\text { Distance from } \\
\text { pressure node }\end{array}$ & & $/ \mathrm{m}$ \\
\hline Greek & & & \\
\hline$\beta_{\mathrm{f}}$ & $\begin{array}{l}\text { Compressibility of } \\
\text { suspending fluid }\end{array}$ & & $/ \mathrm{Pa}^{-1}$ \\
\hline$\beta_{\mathrm{p}}$ & $\begin{array}{l}\text { Compressibility } \\
\text { of particle }\end{array}$ & & $/ \mathrm{Pa}^{-1}$ \\
\hline$\eta$ & $\begin{array}{l}\text { Coefficient of } \\
\text { dynamic viscosity }\end{array}$ & $\begin{array}{c}\left(9 \times 10^{-4} \mathrm{~kg} \mathrm{~m}^{-1} \mathrm{~s}^{-1}\right. \\
\left.\text { for water at } 25^{\circ} \mathrm{C}\right)\end{array}$ & $/ \mathrm{kg} \mathrm{m}^{-1} \mathrm{~s}^{-1}$ \\
\hline$\lambda$ & Wavelength of sound & & $/ \mathrm{m}$ \\
\hline$\rho_{\mathrm{f}}$ & Fluid density & $\begin{array}{l}\left(997 \mathrm{~kg} \mathrm{~m}^{-3} \text { for }\right. \\
\left.\text { water at } 25^{\circ} \mathrm{C}\right)\end{array}$ & $/ \mathrm{kg} \mathrm{m}^{-3}$ \\
\hline$\rho_{\mathrm{p}}$ & Particle density & & $/ \mathrm{kg} \mathrm{m}^{-3}$ \\
\hline
\end{tabular}

\section{Acknowledgements}

The authors are grateful to Dstl (grant reference 2270/002/cbd/ cu013-000010785) and the Medical Research Council's $\mu$ FAST programme (grant reference 57719) for supporting this research.

\section{References}

1 Molecular Cloning: a Laboratory Manual, ed. J. Sambrook, E. F. Fritsch and T. Maniatis, Cold Spring Harbour, NY, 2nd edn., 1989

2 J. M. Ottino and S. Wiggins, Philos. Trans. R. Soc. London Ser. A, 2004, 362, 923.

3 R. K. Gould and W. T. Coakley, Proceedings of Symposium on Finite Amplitude Wave Effects in Fluids, ed. L. Bjørno, IPC, Guildford, UK, 1973, 252-257. 
4 Z. I. Mandralis and D. L. Feke, Chem. Eng. Sci., 1993, 48, 3897. ** First description of continuous flow ultrasonic particle fractionation. 5 K. Yasuda, Jpn. J. Appl. Phys., 1995, 34, 2715.

6 F. Trampler, S. A. Sonderhoff, P. W. S. Pui, D. G. Kilburn and J. M. Piret, Bio/Technology, 1994, 12, 281.

7 J. J. Hawkes, M. S. Limaye and W. T. Coakley, J. Appl. Microbiol., 1997, 82, 39.

8 H. Andersson and A. van den Berg, Sens. Actuators B, 2003, 92, 315.

9 J. J. Hawkes and W. T. Coakley, Sens. Actuators B, 2001, 75, 213.

10 J. J. Hawkes, W. T. Coakley, M. Gröschl, E. Benes, S. Armstrong, P. J. Tasker and H. Nowotny, J. Acoust. Soc. Am., 2002, 111(3), 1259.

11 M. Hill, Y. Shen and J. J. Hawkes, Ultrasonics, 2002, 40, 385.

12 L. Gherardini, C. Cousins, J. J. Hawkes, J. Spengler, S. Radel, H. Lawler, B. Devcic-Kuhar, M. Gröschl, W. T. Coakley and A. McLoughlin, Ultrasound in Medicine and Biology, submitted May 2004.

13 Z. Yang, S. Matsumoto, H. Goto, M. Matsumoto and R. Maeda, Sens. Actuators A, 2001, 93, 266.

14 K. Yasuda, Sens. Actuators B, 2000, 64, 128. * Describes cell and fluid mixing induced by a non-cavitating ultrasonic standing wave field.

15 J. C. Giddings, Sep. Sci. Technol., 1992, 27, 1489.

16 N. Tri, K. Caldwell and R. Beckett, Anal. Chem., 2000, 72, 1823.

17 S. Gupta and D. L. Feke, Chem. Eng. Sci., 1995, 50, 3275.

18 D. A. Johnson and D. L. Feke, Sep. Technol., 1995, 5, 251.

19 CFD Research Corporation, Cummings Research Park, 215 Wynn Drive, Huntsville, AL 35805, USA, User Manual: Version 6.4, 2000.

20 F. M. White, Viscous Fluid Flow, McGraw-Hill, 2nd edn., 1991.

21 F. E. Curry and G. F. Clough, J. Physiol., 2002, 543(3), 729.

22 J. F. Spengler, M. Jekel, K. T. Christensen, R. J. Adrian, J. J. Hawkes and W. T. Coakley, Bioseparation, 2001, 9, 329.

23 L. A. Kuznetsova and W. T. Coakley, J. Acoust. Soc. Am., 2004, 116(4), in press.

24 D. J. Tritton, Physical Fluid Dynamics, Clarendon Press, Oxford, UK, 2nd edn., 1988

25 B. H. Weigl, M. R. Holl, D. Schutte, J. P. Brody and P. Yager, Analytical Methods and Instrumentation Special Issue $\mu T A S 96$, November 1996, 174. * Describes the measurement of diffusion within micro-chambers. 